\title{
RESEARCH
}

Open Access

\section{TSG-6 in conditioned media from adipose mesenchymal stem cells protects against visual deficits in mild traumatic brain injury model through neurovascular modulation}

Kumar Abhiram Jha', Mickey Pentecost ${ }^{2,3}$, Raji Lenin ${ }^{1}$, Jordy Gentry ${ }^{1}$, Lada Klaic ${ }^{2}$, Nobel Del Mar ${ }^{4}$, Anton Reiner ${ }^{4}$, Chuan He Yang ${ }^{5}$, Lawrence M. Pfeffer ${ }^{5}$, Nicolas Sohl ${ }^{2}$ and Rajashekhar Gangaraju ${ }^{1,4^{*}}$ (D)

\begin{abstract}
Background: Retinal inflammation affecting the neurovascular unit may play a role in the development of visual deficits following mild traumatic brain injury (mTBI). We have shown that concentrated conditioned media from adipose tissue-derived mesenchymal stem cells (ASC-CCM) can limit retinal damage from blast injury and improve visual function. In this study, we addressed the hypothesis that TNFa-stimulated gene-6 (TSG-6), an antiinflammatory protein released by mesenchymal cells, mediates the observed therapeutic potential of ASCs via neurovascular modulation.

Methods: About 12-week-old C57BI/6 mice were subjected to 50-psi air pulse on the left side of the head overlying the forebrain resulting in an mTBI. Age-matched sham blast mice served as control. About $1 \mu \mathrm{l}$ of ASCCCM (siControl-ASC-CCM) or TSG-6 knockdown ASC-CCM (siTSG-6-ASC-CCM) was delivered intravitreally into both eyes. One month following injection, the ocular function was assessed followed by molecular and immunohistological analysis. In vitro, mouse microglial cells were used to evaluate the anti-inflammatory effect of ASC-CCM. Efficacy of ASC-CCM in normalizing retinal vascular permeability was assessed using trans-endothelial resistance (TER) and VE-cadherin expression in the presence of TNFa $(1 \mathrm{ng} / \mathrm{ml})$.

Results: We show that intravitreal injection of ASC-CCM (siControl-ASC-CCM) but not the TSG-6 knockdown ASCCCM (siTSG-6-ASC-CCM) mitigates the loss of visual acuity and contrast sensitivity, retinal expression of genes associated with microglial and endothelial activation, and retinal GFAP immunoreactivity at 4 weeks after blast injury. In vitro, siControl-ASC-CCM but not the siTSG-6-ASC-CCM not only suppressed microglial activation and STAT3 phosphorylation but also protected against TNFa-induced endothelial permeability as measured by transendothelial electrical resistance and decreased STAT3 phosphorylation.

(Continued on next page)
\end{abstract}

\footnotetext{
*Correspondence: sgangara@uthsc.edu

'Department of Ophthalmology, University of Tennessee Health Science Center, College of Medicine, 930 Madison Ave, Suite\#768, Memphis, TN 38163, USA

${ }^{4}$ Department of Anatomy and Neurobiology, University of Tennessee Health Science Center, College of Medicine, 855 Monroe Avenue, Suite\#515, Memphis, TN 38163, USA

Full list of author information is available at the end of the article
}

(c) The Author(s). 2019 Open Access This article is distributed under the terms of the Creative Commons Attribution 4.0 International License (http://creativecommons.org/licenses/by/4.0/), which permits unrestricted use, distribution, and reproduction in any medium, provided you give appropriate credit to the original author(s) and the source, provide a link to the Creative Commons license, and indicate if changes were made. The Creative Commons Public Domain Dedication waiver (http://creativecommons.org/publicdomain/zero/1.0/) applies to the data made available in this article, unless otherwise stated. 


\begin{abstract}
(Continued from previous page)
Conclusions: Our findings suggest that ASCs respond to an inflammatory milieu by secreting higher levels of TSG-6 that mediates the resolution of the inflammatory cascade on multiple cell types and correlates with the therapeutic potency of the ASC-CCM. These results expand our understanding of innate mesenchymal cell function and confirm the importance of considering methods to increase the production of key analytes such as TSG-6 if mesenchymal stem cell secretome-derived biologics are to be developed as a treatment solution against the traumatic effects of blast injuries and other neurovascular inflammatory conditions of the retina.
\end{abstract}

Keywords: Endothelial, ERG, OKN, Retina, Microglia, Muller, Paracrine, TBI, MSC, SOD2, Stat3

\section{Introduction}

According to the Defense and Veterans Brain Injury Center (DVBIC) of the Department of Defense, a staggering 383,947 US military service members sustained TBI in 2018 of which $82.3 \%$ of them were classified as mild TBI (mTBI) [1]. While the majority of recorded mTBI cases are related to blast injuries during active duty, some occurred while playing sports or other recreational activities. Despite the implementation of awareness programs and efforts to improve protective equipment to protect those at high risk of blast injuries, the face and brain remain highly vulnerable [2]. Furthermore, secondary displacement of the brain during injury can progress into exacerbated neuropathology and visual deficits that often correlate to acceleration-deceleration concussive insults to optic nerve [3]. Inflammation, oxidative stress, and subsequent cell signaling disturbances stemming from the acceleration-deceleration are causally linked to such neuropathology $[4,5]$. We and others have shown that activation and proliferation of microglial cells are associated with a cycle of inflammation and leads to vascular damage, cell death, and subsequent loss of retinal barrier integrity [6-11]. Consequently, therapies aimed at controlling microglial activation are urgently needed.

Using a validated preclinical animal model of mTBI, we previously reported the beneficial effects of using the secretome of adult mesenchymal stem cells (MSCs) derived from the stromal vascular fraction of human adipose tissue (adipose stem/stromal cells (ASC)) [11]. The concentrated conditioned media from adipose tissuederived mesenchymal stem cells (ASC-CCM) that have been primed with TNF $\alpha$ and IFN $\gamma$ release a variety of cytokines and chemokines among which are extracellular superoxide dismutases (SOD2 and SOD3), immune modulatory proteins like indoleamine 2,3-dioxygenase (IDO), and TNF-stimulated gene 6 protein (TSG-6). Individually, these proteins have been shown to have therapeutic value in numerous animal models, including ophthalmic disease models [11-15]. Our studies indicate that upregulated proteins in the ASC-CCM when ASCs are pre-stimulated with inflammatory cytokines can suppress microglial activation and protect retinal barrier integrity. However, among the many proteins released by ASCs, there remains a need to better understand the role of specific proteins responsible for the observed in vivo therapeutic effect. TSG-6, a multifunctional glycoprotein, has emerged as a potential regulator of inflammation in a variety of diseases including diabetes, corneal injury, asthma, acute pancreatitis, and brain injury [16-20]. Observations that bone marrow MSC-derived TSG-6 inhibit the LPS-mediated pro-inflammatory activation of BV2 cells, a murine microglia-like cell line, point to an important protective role for TSG-6 and led us to focus on understanding the function and effect of mesenchymal stem cell-secreted TSG-6 [21]. Our experiments illustrate that TSG-6 impacts microglia in our mTBI model.

In this study, we generated concentrated conditioned media from ASCs that were treated with siRNA against TSG-6 or a non-targeting control and stimulated with cytokines to determine whether TSG-6 is responsible for the rescue in the visual deficits in our mTBI mouse model $[4,22]$. Furthermore, we have evaluated the effects of TSG-6 on BV2 cells and retinal endothelial cells in vitro. Our data demonstrate TSG-6-dependent suppression of microglial activation in vivo and protection against retinal barrier integrity in vitro suggesting a key role for TSG-6 in ASC-CCM.

\section{Materials and methods TSG-6 knockdown in ASC culture and conditioned medium preparation}

Commercial ASCs were purchased from Lonza (Walkersville, MD, USA; Cat\# PT-5006, Lot\# 0000535975). To knock down TSG-6 expression, ASCs were seeded into T75 flasks at a density of 15,000 cells $/ \mathrm{cm}^{2}$ at $37{ }^{\circ} \mathrm{C}$ and $5 \%$ $\mathrm{CO}_{2}$ in $15 \mathrm{ml}$ of complete media (MEM-alpha with $10 \% \mathrm{FBS}$ ). At $8 \mathrm{~h}$ post-seeding, cells were transfected for 16 h with negative control siRNA (Cat\#: 4390844, Ambion) or a validated siRNA against TSG-6 (Cat\#4392420, Ambion) using Lipofectamine ${ }^{\circ}$ RNAiMAX reagent (Invitrogen, Cat\#: 13778150). ASCs were subsequently washed twice with DPBS and then primed with $20 \mathrm{ng} / \mathrm{ml}$ TNF $\alpha$ (R\&D Systems) and $10 \mathrm{ng} / \mathrm{ml}$ IFN $\gamma$ (R\&D Systems) in basal media for $24 \mathrm{~h}$. ASCs were again washed twice with DPBS to remove cytokines and then cultured in basal media for an additional $24 \mathrm{~h}$ at which point that the conditioned media 
were collected and the cells were lysed in $1.5 \mathrm{ml}$ of $100 \mathrm{mM}$ Tris-HCL pH 8.0, $150 \mathrm{mM} \mathrm{NaCL}, 5 \mathrm{mM}$ EDTA, 5\% glycerol, and $0.1 \%$ NP40 supplemented with Halt ${ }^{\text {Tw }}$ Protease Inhibitor Cocktail (Thermo Fisher Scientific). The conditioned media were filtered through a $0.45-\mu \mathrm{m}$ syringe filter and then concentrated $\sim 20 \times$ using a $3-\mathrm{kDa}$ molecular weight cutoff Amicon Ultra-15 centrifugal concentrator and desalted by the addition and concentration of $14 \mathrm{ml}$ DPBS twice. The total amount of protein in the desalted, concentrated conditioned medium samples (primed or unprimed siControl-ASC-CCM and siTSG-6-ASCCCM) were measured using the Qubit Protein Assay Kit and a Qubit fluorimeter. Aliquots were stored at $-80^{\circ} \mathrm{C}$ and normalized to the same concentration with DPBS for all comparative assays.

\section{Western blot analysis}

Concentrated conditioned medium samples and cell lysates were assessed by immunoblot analysis for TSG-6, COX IV, and TIMP-1 as described by us previously [11]. Total STAT3 and phosphorylated STAT3 (pY705-STAT3) were assessed as we previously described [23].

\section{Nitric oxide release assay}

The nitrite concentration in microglial cell culture media pre-incubated with primed siControl ASC-CCM or primed siTSG-6 ASC-CCM was determined using the Greiss Reagent System as described previously [11].

Microglial and retinal endothelial cell culture and activation The mouse microglial cell line, BV2, was a kind gift from Professor Grace Sun, Ph.D., University of Missouri, Columbia, MO. Activation of BV2 cells was performed as we described previously [11]. Human retinal endothelial cells (HREC; Cell Systems, Inc.) were seeded at a density of $4 \times 10^{4}$ cells $/ \mathrm{cm}^{2}$ and grown for $24 \mathrm{~h}$ in growth media. Cells were switched to serum-free media, preincubated with and without primed siControl-ASC-CCM or primed siTSG6-ASC-CCM $(100 \mu \mathrm{g} /$ well $)$ for $6 \mathrm{~h}$, and then activated with TNF $(1 \mathrm{ng} / \mathrm{ml}$; Sino Biological, Inc.) for $18 \mathrm{~h}$ and proceeded with Western blot analysis.

\section{Gene expression analysis}

Retinal extracts from TBI mice were assessed for gene expression changes using NanoString Counter ${ }^{\bullet}$ multiplex analysis with the neuropathology panel as we previously described [23]. Briefly, in each group, four to nine individual mouse retinas were analyzed 4 weeks post-blast injury. The nCounter Dx Analysis System uses gene-specific probe pairs that hybridize directly to mRNA samples. A reporter probe carries the fluorescent signal; a capture probe allows the complex to be immobilized for data collection. Analysis of data QC, normalization, and differential gene expression data was analyzed using nSolver 4.0 with nCounter Advanced Analysis (Version 2.1.115). The expression levels of representative gene transcripts (Table 1) were further confirmed by real-time quantitative PCR using TaqMan assays and analyzed using 2-DDCt method. Gene expressional analysis carried out using total RNA isolated from BV2 cells was described by us recently [11].

\section{Immunocytochemistry}

Immunocytochemistry was performed to reveal the localization of Iba1 and F-actin in the BV2 cells as described by us recently [11]. Quantification of pixel intensities (relative fluorescence units) for Iba1 was analyzed from at least five images from different locations per well and expressed as an average of the experimental groups. Immunocytochemistry for VE-cadherin in HREC was performed by a method as we described previously [24].

\section{Retinal endothelial cell permeability in vitro}

Measurements of trans-endothelial electrical resistance (TER) were performed according to our previously published method that utilizes the measurement of electric cell-substrate impedance sensing (ECIS; Applied Biophysics, Troy, NY) [11]. Changes in the resistance upon exposure to TNF $\alpha(1 \mathrm{ng} / \mathrm{ml})$ were monitored for up to

Table 1 Expression levels of representative gene transcripts

\begin{tabular}{lll}
\hline Genes & TaqMan assay ID & Reference sequence \\
\hline 18S ribosomal RNA (18s) & Mm04277571_s1 & NR_003278.3 \\
Interleukin 1 beta (II1 $\beta)$ & Mm00434228_m1 & NM_008361.3 \\
Cluster of differentiation 86 (Cd86) & Mm004445543_m1 & NM_019388.3 \\
Glial fibric acid protein (GFAP) & Mm01253030_m1 & NM_001131020.1 \\
Interferon regulatory factor 8 (Irf8) & Mm00492567_m1 & AK018533.1 \\
V-erb-b2 erythroblastic leukemia viral oncogene homolog 3 (Erbb3) & Mm01159999_m1 & NM_010153.1 \\
Fas/TNF receptor superfamily member 6 (Fas) & Mm01204974_m1 & NM_007987.2 \\
Vascular cell adhesion molecule 1 (Vcam1) & Mm01320973_m1 & NM_011693.3 \\
Endothelin 2 (Edn2) & Mm00432983_m1 & NM_007902.2 \\
\hline
\end{tabular}


$18 \mathrm{~h}$ with siControl-ASC-CCM or siTSG-6-ASC-CCM. Resistance values at $4000 \mathrm{~Hz}$ for multiple wells were normalized to an identical starting resistance value, averaged, and presented as normalized resistance over time.

\section{Animals and blast injury study groups}

The TBI mouse model was performed as described previously [4]. Experiments were performed in two batches; eight animals in the sham blast group received saline; eight animals in the 50-psi blast group received saline; ten animals in the 50-psi blast group received $1 \mu \mathrm{l}(\sim 68 \mu \mathrm{g} / \mathrm{ml}$ of total protein) of primed siControl-ASC-CCM; and ten animals in the 50-psi blast group received $1 \mu \mathrm{l}(\sim 68 \mu \mathrm{g} / \mathrm{ml}$ of total protein) of primed siTSG-6-ASC-CCM. Intravitreal injections were performed with a 30 -gage microsyringe (Hamilton, Reno, NV), on the temporal side of the eye, $2 \mathrm{~mm}$ posterior and parallel to the limbus. Various analyses were performed 4 weeks after the intravitreal injections (Additional file 1: Figure S1).

\section{Optokinetic reflex measurements}

To assess visual function, optokinetic reflex measurements were made 4 weeks post-blast injury as we described previously [11]. Visual acuity was assessed at 100\% contrast by varying spatial frequency threshold. Contrast sensitivity was assessed in mice by varying the contrast at 0.042 cycles per degree $(\mathrm{c} / \mathrm{d})$ of the spatial frequency threshold.

\section{Electroretinogram measurement}

Scotopic threshold electroretinogram (ERG) recordings were obtained using the Espion E2 ERG system (Diagnosys LLC, Lowell, MA) as we described previously [25]. Mice were presented with different flashes of increasing intensity $(0.0025,0.025,0.25,2.5$, $25 \mathrm{~cd} \mathrm{~s} \mathrm{~m}^{2}$ ), each repeated five times, with an interstimulus interval ranging from $20 \mathrm{~s}$ for dim flashes to $1 \mathrm{~min}$ for the brightest flashes. Three to five ERG traces at each flash luminance were averaged to measure b-wave amplitude.

\section{Tissue preparation and immunohistochemistry}

Post-euthanasia eyes from all groups were enucleated, and retinal eyecups were processed for immunohistochemical analysis of GFAP expression as we described previously [11]. Quantification of pixel intensities (relative fluorescence units) of GFAP-immunolabeled Müller cells was analyzed from at least three sections (from NFL to RPE) per eye, three areas per retina (two mid-peripheral and a central) by an investigator blinded to the groups and expressed as mean intensity per $100,000 \mu \mathrm{m}^{2}$ of the retina.

\section{Statistical analysis}

Results are expressed as mean \pm SEM for all experiments. Pairwise $t$ tests were run in order to calculate the $p$ values for comparisons between the individual groups. One way ANOVA followed by post hoc $t$ tests with the Bonferroni correction was used for multiple group comparisons using GraphPad Prism software. For NanoString analysis, the signal intensities (arbitrary units) for each target from four to nine individual retina were averaged, and pairwise group comparisons were made. Any expression below 0.5 -fold was considered downregulated; $0.5-1.5$-fold considered unchanged, and any value above 1.5 -fold was considered upregulated. All samples with correlation coefficients $>0.8$ within the biological group were included in the study. Heat maps were generated by unsupervised clustering analyses using Spearman correlation in the nSolver program. In all analyses, a $p$ value $<0.05$ was considered statistically significant.

\section{Results \\ Depletion of TSG-6 from the concentrated conditioned medium from cytokine primed ASCs}

Previously, we have shown that TSG-6 secretion by ASCs primed with inflammatory cytokines continued after their removal, allowing for the collection of antiinflammatory conditioned media [11]. In this study, ASCs were first treated with TSG-6 siRNA or control siRNA and then primed with IFN $\gamma$ and TNF $\alpha$ in serum-free media to permit conditioning of serumand cytokine-free media with the cell secretome according to the schema in Fig. 1a and as described in the "Materials and methods" section. The conditioned media were collected, filtered to remove cell debris, and then concentrated and desalted using 3-kDa molecular weight cutoff centrifugal filters. Concurrently, the cells were lysed for Western blot analyses. As shown in Fig. 1b, transient transfection of ASCs with TSG-6 siRNA resulted in a significant reduction in TSG-6 levels both in the cell lysates and concentrated conditioned media as compared to cells that were treated with control siRNA and primed with cytokines. COXIV served as an internal control for cell lysates. TIMP1 served as an internal control for secreted proteins in the concentrated conditioned media. Both analytes were unaffected with TSG-6 knockdown suggesting no adverse effect of TSG-6 knockdown in ASCs. Moreover, the specificity of TSG-6 knockdown was evidenced by the levels of IDO1 and SOD2 being upregulated by cytokine treatments but unaffected by siRNA treatments (Additional file 2: Figure S2). 
A

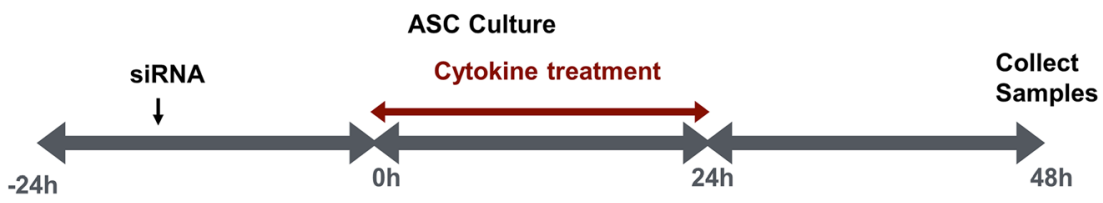

B

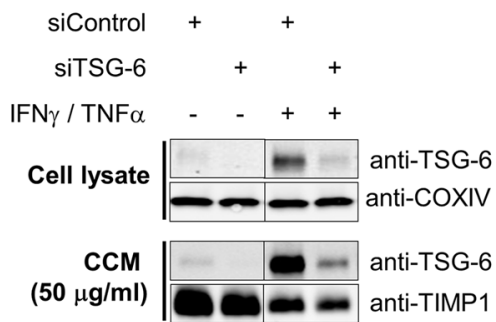

Fig. 1 Depletion of TSG-6 from cytokine-primed ASC conditioned medium. a Schema for preparation of siRNA-mediated knockdown of TSG-6 in conditioned medium from exogenous cytokine-stimulated ASCs. b Immunoblot analysis of TSG-6 in cell lysates and CCM. COXIV and TIMP1 in CCM remained unchanged. Data represent mean \pm SEM from at least three technical replicates

\section{TSG-6-depleted ASC-CCM fails to suppress microglial activation}

We previously showed that ASC-CCM could inhibit the LPS-mediated pro-inflammatory activation of BV2 cells, a murine microglia-like cell line [11]. To address the role of TSG-6 in these observed effects, we performed experiments with BV2 cells. While primed siControl-ASC-CCM could suppress the production of nitrite by LPS-treated BV2 cells, primed siTSG-6-ASC$\mathrm{CCM}$ at the same total protein concentration $(5 \mu \mathrm{g} / \mathrm{ml})$ failed to suppress nitrite release $(p<0.01$, Fig. $2 \mathrm{a})$. Interestingly neither unprimed siControl-ASC-CCM nor unprimed siTSG-6-ASC-CCM could suppress nitrite release, confirming our previous observations that cytokine priming is essential to generating sufficient release of TSG-6 by ASCs for therapeutic effect.

Since the production and release of cytokines play a central role in the microglia-mediated inflammatory action and their regulation of gene expression, we next assessed the expression of IL-1 $\beta$ and CD-86 (early and late markers of the M1 phenotype of microglia) and arginase-1 (a marker of M2 phenotype of microglia) by real-time PCR. Whereas the gene transcripts of IL- $1 \beta(p<0.001)$ and CD-86 $(p<0.001)$ was significantly increased in BV2 cells treated with LPS and IFN $\gamma$, the expression of Arg- 1 decreased $(p<0.001)$ compared to untreated cells confirming the activation of BV2 cells. In agreement with the nitrite release data, only primed siControl-ASC-CCM significantly reduced IL-
$1 \beta(p<0.001)$, CD-86 $(p<0.001)$, and Arg-1 $(p<0.001)$ gene expression (Fig. 2b), while primed siTSG-6-ASCCCM failed to suppress gene expression in BV2 cells. Again, neither unprimed siControl-ASC-CCM nor unprimed siTSG-6-ASC-CCM could suppress BV2 gene expression.

\section{TSG-6-depleted ASC-CCM fails to preserve resting cell morphology in LPS and IFN- $\gamma$-stimulated BV2 cells}

Previously, we have shown that ASC-CCM could preserve the resting cell morphology of BV2 cells subsequent to microglial activation $[11,26]$. To address the role of TSG-6 in this pathway, we assessed the morphological changes in BV2 cells by inverted phase contrast microscope and F-actin immunostaining. While primed siControl-ASC-CCM preserved the morphology of BV2 cells with well-defined soma with distal arborization similar to control cells, cells treated with primed siTSG-6-ASC-CCM failed to preserve the morphology and were morphologically similar to BV2 cells treated with LPS and IFNy with fewer branches, predominately appearing amoeboid (Additional file 3: Figure S3). Neither unprimed siControl-ASC-CCM nor unprimed siTSG-6-ASCCCM affected the morphology of activated BV2 cells. Previously, we have also shown a correlation of BV2 cell activation with increased ionized calcium-binding adapter molecule 1 (Iba1) immunostaining [11, 27]; here, we assessed the role of TSG-6 in the increased 


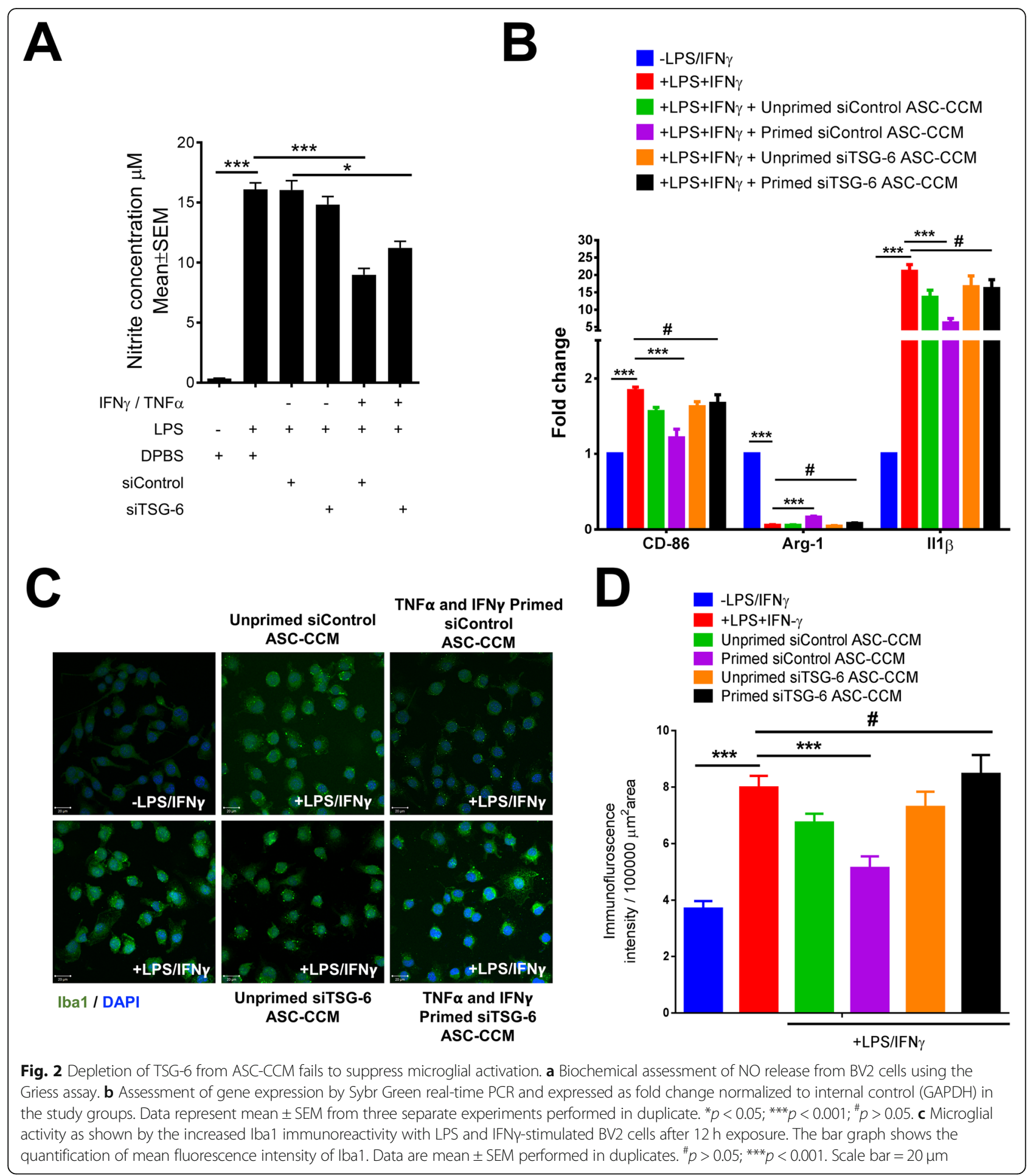

Iba1 staining. BV2 cells treated with LPS and IFN $\gamma$ demonstrated an increase in Iba1 immunostaining. In contrast, cells that were pre-incubated with primedsiControl-ASC-CCM, but not primed-siTSG-6-ASCCCM, demonstrated a decrease in Iba1 immunoreactivity (Fig. 2c). The mean total pixel intensity of Iba1 expression in the control group was $3.7 \pm 0.26$, while the pixel intensity of Ibal expression in cells treated with LPS/ IFN $\gamma$ was $7.98 \pm 0.41$ (mean intensity/10, $\left.000 \mu \mathrm{m}^{2} ; \quad p<0.001\right)$. Cells pretreated with primed siControl-ASC-CCM and then treated with LPS/ IFN $\gamma$ showed reduced Iba1 expression $(5.14 \pm 0.4$ mean 
intensity $\left./ 10,000 \mu \mathrm{m}^{2} ; p<0.001\right)$ but not cells pretreated with primed siTSG-6-ASC-CCM $(8.46 \pm 0.67$ mean intensity/10,000 $\mu^{2} ; p<0.05$; Fig. 2d).

\section{TSG-6-depleted ASC-CCM fails to protect against TNFa-} induced loss of endothelial barrier integrity

Previously, we have shown that ASC-CCM could preserve retinal barrier function in an in vitro model [11]. To address the role of TSG-6 in this pathway, transendothelial electrical resistance (TER) was measured in human retinal endothelial cells (HRECs) exposed to TNF $\alpha$. Whereas TNF $\alpha$-treated HREC demonstrated sustained reduction in the barrier integrity as evidenced by decreased TER at the 20-h time point (TNF $\alpha, 0.83 \pm$ 0.01 ; control, $1.0 ; p<0.001$ ), only cells pretreated with primed siControl-ASC-CCM, but not primed siTSG-6ASC-CCM, partially rescued the loss in TER $(0.95 \pm$ $0.04, p<0.05$, Fig. 3a). Since we found that alterations in TER coincided with a change in VE-cadherin distribution [24], we also assessed VE-cadherin distribution. While control untreated cells displayed a continuous pattern of VE-cadherin staining associated with the lateral cell borders, treatment with TNF $\alpha$ caused a disruption in the pattern of VE-cadherin with punctate staining on the cell surface. On the other hand, HREC treated simultaneously with primed siControl-ASC-CCM and challenged with TNF $\alpha$ demonstrated restoration of VE-cadherin staining similar to control cells. Interestingly, cells pretreated with siTSG-6 ASC-CCM failed to rescue the VEcadherin distribution when challenged with TNF $\alpha$ (Fig. 3b). Taken together, these findings suggest that depletion of
TSG-6 from ASC-CCM fails to protect against the TNF $\alpha$ induced loss of endothelial barrier integrity.

\section{TSG-6-depleted ASC-CCM fails to suppress} phosphorylated STAT3 in stimulated BV2 and HRECs Previously, it was shown that TSG-6 regulates the activation of STAT proteins downstream of LPS signaling in $T_{S G 6^{-/}}$mice [28]. Since STAT3 has been implicated in promoting inflammatory pathways, we reasoned that TSG-6 through a STAT3 pathway might play an antiinflammatory role and suppress microglial activation. To this end, we measured total STAT3 and phosphorylated STAT3 in BV2 microglial cells that were activated with LPS and IFN- $\gamma$ with and without primed siControl-ASCCCM or primed siTSG-6-ASC-CCM. While primed siControl-ASC-CCM suppressed STAT3 phosphorylation in BV2 cells treated with LPS and IFN- $\gamma$, primed siTSG-6-ASC-CCM failed to mitigate STAT3 phosphorylation (Fig. 4a). Because STAT3 is also implicated in endothelial permeability [29], we measured STAT3 levels in HRECs that were activated with TNF $\alpha$ with and without primed siControl-ASC-CCM or primed siTSG6-ASC-CCM. While primed siControl-ASC-CCM suppressed STAT3 phosphorylation in HRECs treated with TNF $\alpha$, primed siTSG-6-ASC-CCM failed to mitigate STAT3 phosphorylation (Fig. 4b).

TSG-6-depleted ASC-CCM fails to suppress visual deficits in blast-induced damage

Previously, we have shown that ASC-CCM could preserve visual acuity and contrast sensitivity after blast injury in our

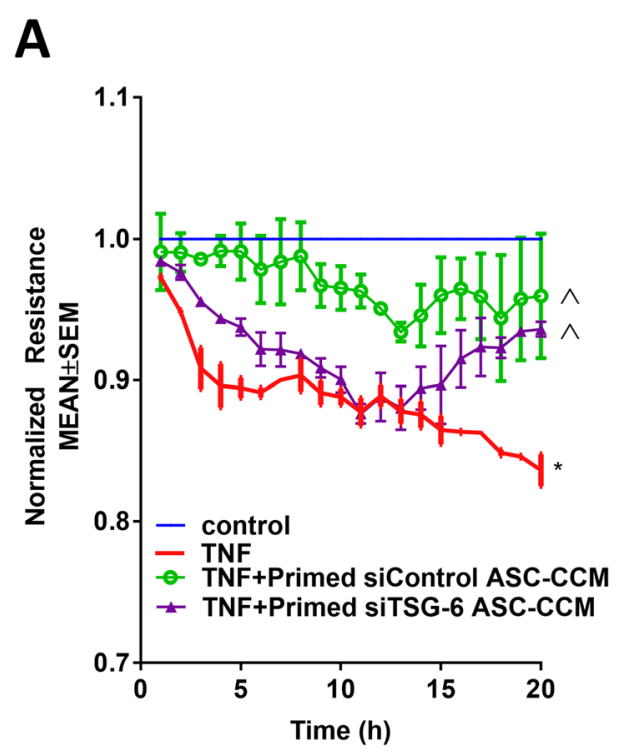

B

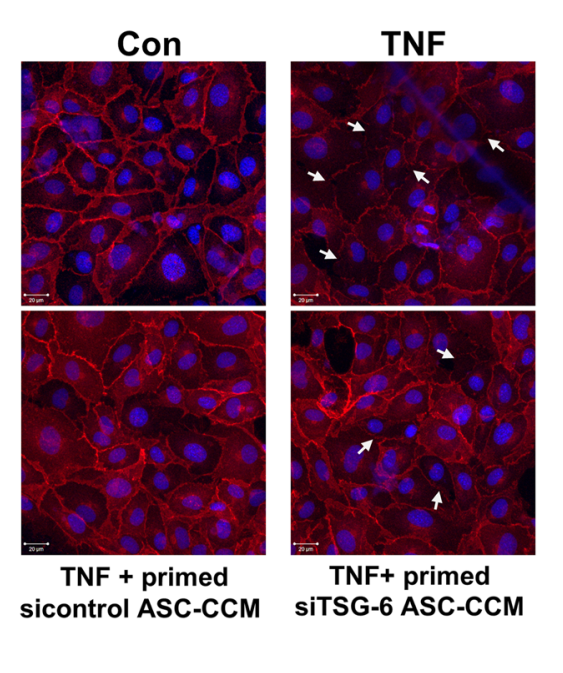

Fig. 3 Depletion of TSG-6 from ASC-CCM fails to suppress TNFa-induced trans-endothelial resistance. a Trans-endothelial resistance is protected by siControl ASC-CCM, but not by siTSG-6 TSG-6 ASC-CCM in vitro. Representative ECIS tracings plotted as normalized resistance expressed as mean \pm SEM of a single experiment performed in replicates with similar data from two independent experiments. ${ }^{*} p<0.001$ compared to control, $\wedge p<0.05$ compared to TNF. $\mathbf{b}$ Representative confocal immunofluorescence images of VE-cadherin in HREC. White arrows indicate loss of cell-cell contacts 


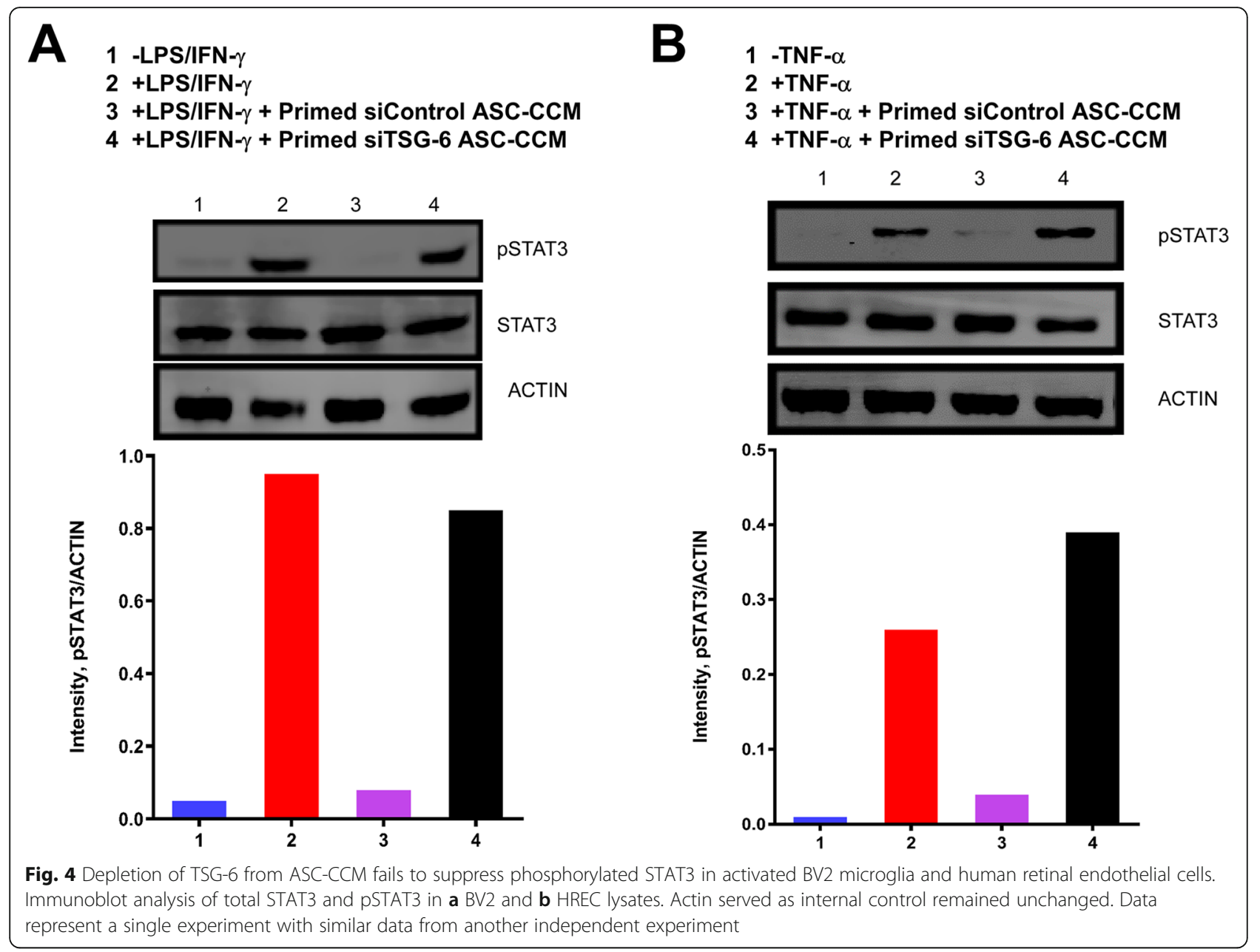

mTBI model [11]. To understand the role of TSG-6 in the observed beneficial effects, we performed optokinetic measurements and electroretinogram measurements 4 weeks after blast injury in the sham blast group that received saline, 50-psi blast group that received saline, 50-psi blast group that received primed siControl-ASC-CCM, and 50psi blast group that received primed siTSG-6-ASC-CCM. While sham blast mice had a visual acuity of $0.403 \pm 0.00 \mathrm{c} /$ $\mathrm{d}$ in the left eye, visual acuity in blast mice was significantly decreased in the left eye $(0.300 \pm 0.005$; sham, $0.406 \pm 0.01$ $\mathrm{c} / \mathrm{d}, p<0.001)$. Interestingly, mice that received primed siControl-ASC-CCM, but not primed siTSG-6-ASC-CCM, demonstrated a significant improvement in visual acuity (primed siControl-ASC-CCM, $0.362 \pm 0.006 \mathrm{c} / \mathrm{d}$; primed siTSG-6-ASC-CCM, $0.321 \pm 0.004$ c/d, $p<0.001$, Fig. 5a). Similarly, the contrast sensitivity of blast mice showed an increase in the contrast needed to detect $0.042 \mathrm{c} / \mathrm{d}$ in the left eye (blast, $89.54 \% \pm 1.35$; sham, $6.08 \% \pm 1.08, p<0.001$ ), with a significant improvement observed in mice receiving only primed siControl-ASC-CCM but not primed siTSG-6ASC-CCM in the left eye (primed siControl-ASC-CCM,
$32.68 \% \pm 4.11$; primed siTSG-6-ASC-CCM, 70.03\% \pm 1.29 , $p<0.001$; Fig. 5b).

ERG is one of the most widely used measures of functional performance/deficits in the visual pathway in diabetic rodents [30, 31]. Dark-adapted scotopic ERG responses were recorded from both eyes of all study groups. With increasing flashlight intensities starting from 0.0025 to $25 \mathrm{~cd} \mathrm{~s} \mathrm{~m}^{2}$, an expected increase in amplitudes could be discerned with the most robust changes detected at $25 \mathrm{~cd} \mathrm{~s} \mathrm{~m} \mathrm{~m}^{2}$ in sham blast mice. The

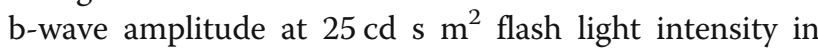
the sham blast group of animals were $455.3125 \pm 8.8 \mu \mathrm{V}$ which significantly decreased to $410.888 \pm 13.08 \mu \mathrm{V}$ in blast injury mice that received saline $(p<0.007$, Additional file 4: Figure S4). On the other hand, intravitreal injection of both primed siControl-ASC-CCM and primed siTSG-6-ASC-CCM resulted in improvement in

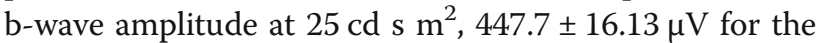
blast-primed siControl-ASC-CCM group $(p<0.04)$, and $469.09 \pm 18.64 \mu \mathrm{V}$ for the blast-primed siTSG-6-ASCCCM group (Additional file 4: Figure S4; $p<0.008$ ). 

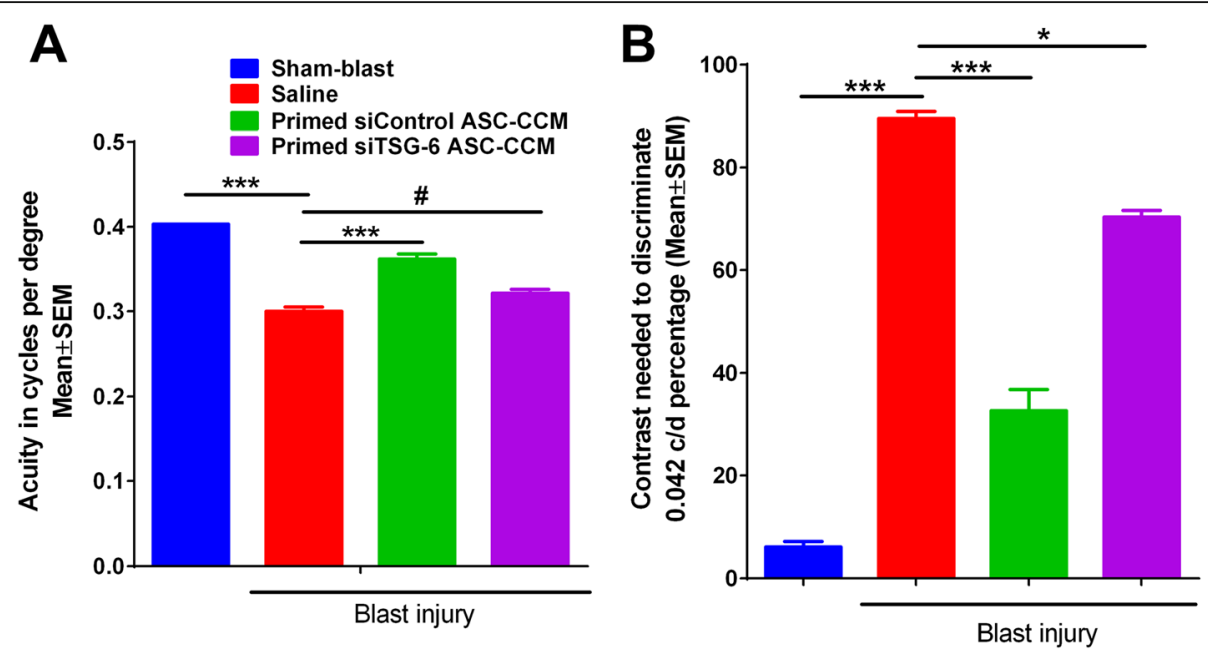

Fig. 5 A depletion of TSG-6 from ASC-CCM fails to improve visual acuity and contrast sensitivity in blast injury mice. a Visual acuity was measured by presenting black and white bars of varying spatial frequencies at 100\% contrast. b Contrast sensitivity was measured by changing the contrast gradient that generates tracking at a fixed spatial frequency of $0.042 \mathrm{c} / \mathrm{d}$. Contrast sensitivity in mice is expressed as a percentage, with a higher percent contrast requirement indicating less contrast sensitivity. Data represent mean \pm SEM from $n=10-20$ animals/group. ${ }^{*} p<0.05 ;{ }^{* * *} p<0.001 ;{ }^{\#} p>0.05$

TSG-6-depleted ASC-CCM fails to reduce blast-induced expression of the glial fibrillary acidic protein (GFAP) in Müller cells

Previously, we have shown that ASC-CCM could suppress increased GFAP expression in Müller glial cells in blast injury mouse retina [11]. To address the role of TSG-6 in the observed beneficial effects, we assessed GFAP immunoreactivity in all experimental groups. While in the blast group with saline, GFAP expression was found in the Muller glial processes that extended into the inner retina, only blast mice that received primed siControl-ASC-CCM but not the primed siTSG-6-ASC-CCM demonstrated lower levels

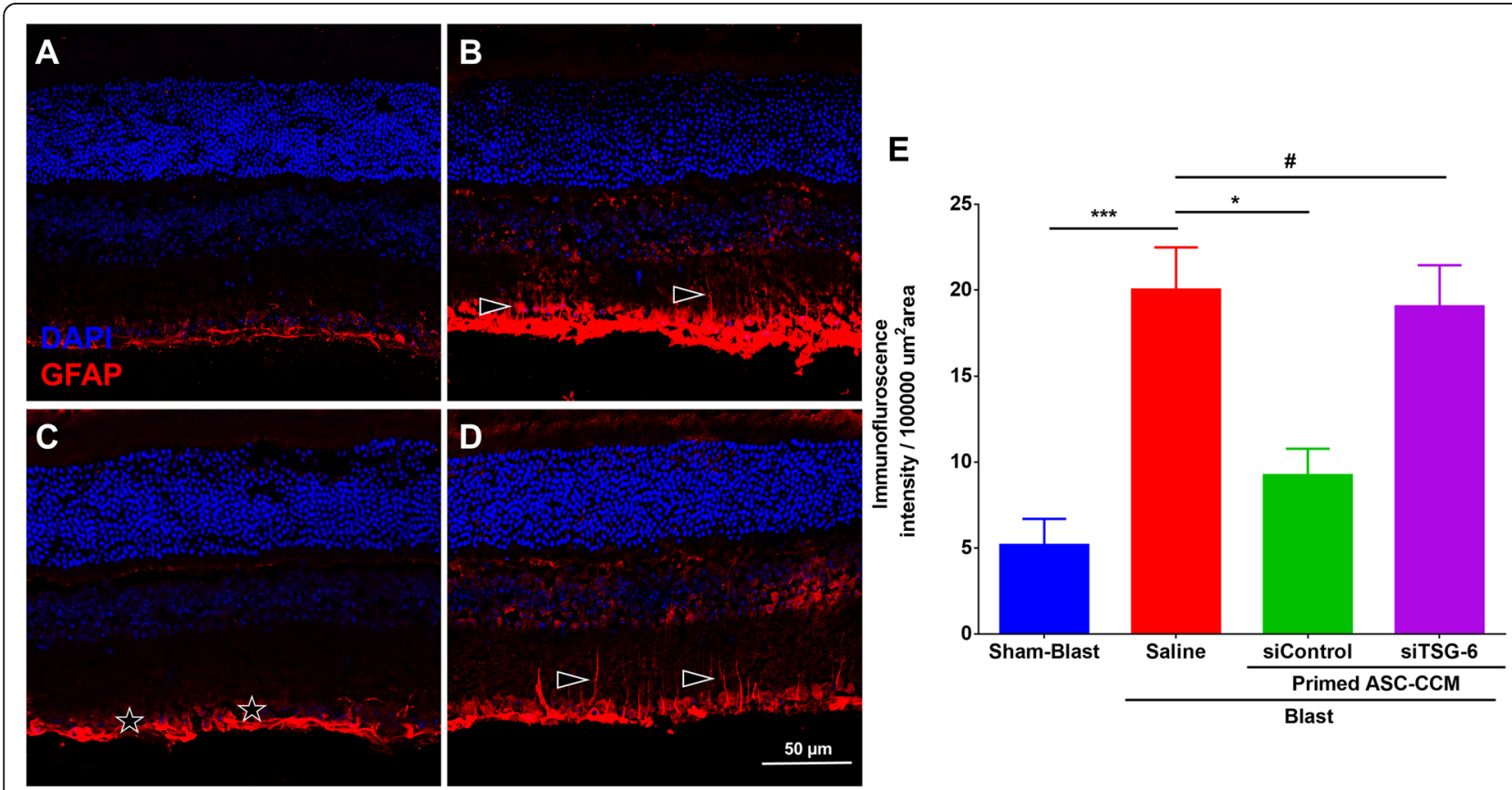

Fig. 6 Depletion of TSG-6 from ASC-CCM fails to improve retinal GFAP expression in blast injury mice. GFAP immunoreactivity in the retina of a sham and $\mathbf{b}$ blast injury animals that received saline, $\mathbf{c}$ blast injury animals that received primed siControl ASC-CCM, and $\mathbf{d}$ blast injury animals that received siTSG-6 ASC-CCM. e ImageJ quantification of GFAP intensity. Data represent mean \pm SEM from $n=5-9$ animals/group. ${ }^{*} p<0.01$; ${ }^{* * *} p<0.001$. Scale bar $=50 \mu \mathrm{m}$ 
of GFAP expression (Fig. 6). The mean total pixel intensity of GFAP expression measured from NFL to retinal pigment epithelium in the normal sham group retina was $5.18 \pm 1.5$ while the blast group with saline was $20.02 \pm 2.46$ (mean intensity $/ 100,000 \mu \mathrm{m}^{2}$ area; $p<0.002, n=5$; Fig. 6e). On the other hand, blast mice with primed-siControl-ASC-CCM showed reduced GFAP expression $(9.24 \pm 1.53$ mean intensity $/ 100,000 \mu \mathrm{m}^{2}$ area; $\left.p<0.01, n=9\right)$ whereas blast mice with primed-siTSG-6-ASC-CCM remained high (19.05 \pm 2.39 mean intensity $/ 100,000 \mu \mathrm{m}^{2}$ area; $p>0.01, n=9$ ).

\section{TSG-6-depleted ASC-CCM fails to suppress pro-} inflammatory gene transcripts in blast mice retina

Previously, we demonstrated the anti-inflammatory capacity of ASC-CCM in suppressing the expression of Il1 $\beta$ and CD86 (early and late markers of the M1 phenotype of microglia) 4 weeks after blast injury [11]. In this study, to address the role of TSG-6 in the observed effects, retinal extracts from blast mice from all groups were assessed for gene expression by NanoString multiplex analysis followed by TaqMan probe-based real-time PCR analyses. The heat maps (Fig. 7a; Additional file 5: Figure
S5A) and volcano plots (Additional file 5: Figure S5B) show several interesting comparisons between the sham blast and blast injury animals that received intravitreal saline injections. A number of genes that are involved in neuroinflammation, neurotransmission, metabolism, neuroplasticity, development and aging, and neuron-glia interactions are increased $>2$-fold in blast injury compared to sham blast. Among these, genes involved in neuroinflammation (C3, complement factor 3; Tlr2, Tolllike receptor 2; Irf8, interferon regulatory factor 8; Fas, TNF receptor superfamily member 6; Lox, lysyl oxidase) are increased in blast injury but were decreased in blast animals that received siControl ASC-CCM but not siTSG-6 ASC-CCM. Similarly, genes involved in neurotransmission (Erbb3, erb-b2 receptor tyrosine kinase 3; Slc6a4, solute carrier family 6 (neurotransmitter transporter, serotonin), member 4) are increased in blast injury but were decreased in blast animals that received primed siControl ASC-CCM but not by primed siTSG-6 ASCCCM (Additional file 5: Figure S5C).

To confirm these observations, individual TaqMan assays for representative genes were performed as we

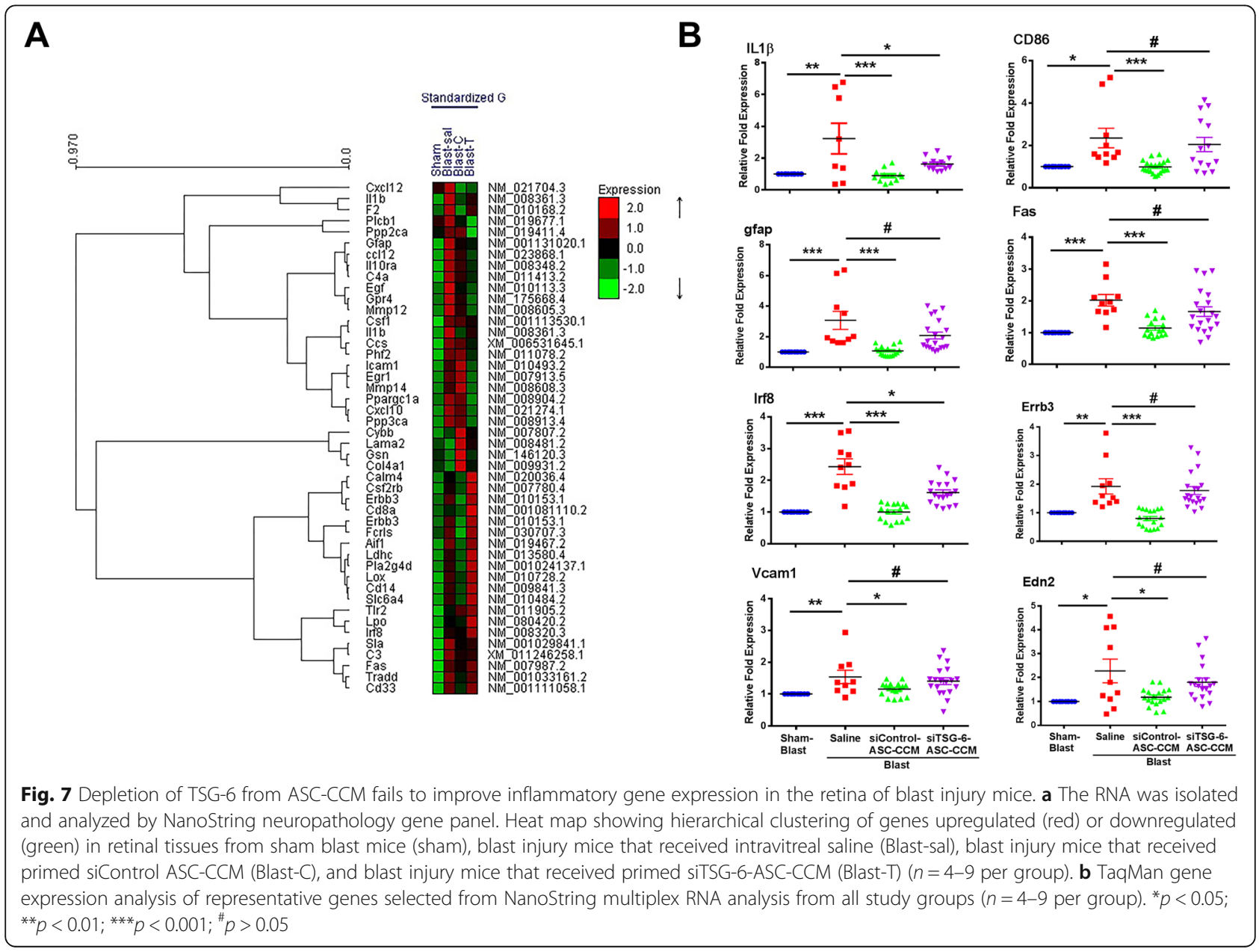


described previously [11]. Figure $7 \mathrm{~b}$ shows a representative scatter plot data of individual genes in all four groups of mice. Blast injury mice receiving saline had significantly increased abundance of gene transcripts involved in microglial activation (Il1 $\beta$, CD86, Gfap), endothelial activation (Vcam1, Edn2), neuroinflammation (Fas, Irf8), and neurotransmission (Erbb3) compared to sham mice. Interestingly, four out of the six genes assessed were significantly changed in blast mice that received primed siControl-ASC-CCM but not the primed siTSG-6-ASC-CCM. The normalized fold change in the expression of Il1 $\beta$ (blast vs blast/primed-siControl-ASCCCM, $3.24 \pm 0.96$ vs $0.89 \pm 0.09, p<0.001$; blast vs blast/ primed-siTSG-6-ASC-CCM, $3.24 \pm 0.96$ vs $1.63 \pm 0.09$, $p<0.037$ ), CD86 (blast vs blast/primed-siControl-ASCCCM, $2.35 \pm 0.51$ vs $0.98 \pm 0.07, p<0.002$; blast vs blast/ primed-siTSG-6-ASC-CCM, $2.35 \pm 0.51$ vs $2.04 \pm 0.33$, $p>0.05$ ), Gfap (blast-saline vs blast/primed-siControlASC-CCM, $3.07 \pm 0.58$ vs $1.07 \pm 0.08, p<0.001$; blastsaline vs blast/primed-siTSG-6-ASC-CCM, $3.07 \pm 0.58$ vs $2.08 \pm 0.22, p>0.05$ ), Fas (blast-saline vs blast/primedsiControl-ASC-CCM, $2.02 \pm 0.18$ vs $1.14 \pm 0.02, p<0.001$; blast-saline vs blast/primed-siTSG-6-ASC-CCM, $2.02 \pm$ 0.18 vs $1.66 \pm 0.15, p>0.05$ ), Irf8 ((blast-saline vs blast/ primed-siControl-ASC-CCM, $2.4 \pm 0.24$ vs $1.001 \pm 0.06$, $p<0.001$; blast-saline vs blast/primed-siTSG-6-ASCCCM, $2.4 \pm 0.24$ vs $1.61 \pm 0.08, p<0.01$ ), Erbb3 (blast-saline vs blast/primed-siControl-ASC-CCM, $1.92 \pm 0.26$ vs $0.79 \pm 0.06, p<0.003$; blast-saline vs blast/primed-siTSG6-ASC-CCM, $1.92 \pm 0.26$ vs $1.77 \pm 0.13, p>0.05$ ), Vcam 1 (blast-saline vs blast/primed-siControl-ASC-CCM, $1.76 \pm$ 0.27 vs $1.001 \pm 0.06, p<0.001$; blast-saline vs blast/ primed-siTSG-6-ASC-CCM, $1.76 \pm 0.27$ vs $1.53 \pm 0.16$, $p<0.01$ ), and End2 (blast-saline vs blast/primed-siControl-ASC-CCM, $2.27 \pm 0.49$ vs $1.17 \pm 0.03, p<0.003$; blast-saline vs blast/primed-siTSG-6-ASC-CCM, $2.27 \pm$ 0.49 vs $1.90 \pm 0.19, p>0.05)$ gene transcripts is shown in Fig. $7 \mathrm{~b}$.

\section{Discussion}

Our previous published study demonstrated the beneficial effects of concentrated conditioned medium from cytokine-primed ASC in the mTBI mouse model. It was demonstrated that treatment prevented the activation of microglia cells after an injury that likely contributed to the overall prevention of vision loss in these animals. It was also observed that TSG-6 is upregulated in ASCCCM by about fivefold upon stimulation with TNF $\alpha$ and IFN $\gamma$ with no changes in TIMP1 or COXIV, suggesting a pivotal role for TSG- 6 in modulating inflammation and the injury response [11]. The present study provides substantial evidence that microglial activation is significantly prevented via TSG-6. When we removed TSG-6 from the ASC-CCM, the beneficial effects of treatment in the mTBI model were attenuated. Interestingly, we observed that the role of TSG-6 is not limited to suppression of microglial activation but likely extends to the protection against loss of endothelial barrier integrity based on our in vitro findings. In support of our data, several other studies have shown the beneficial effects of TSG-6 secreted by ASCs or MSCs in disease models such as severe acute pancreatitis [17], acute lung injury [32], corneal injury [20], asthma [19], diabetic corneal epithelial wound healing [18], myocardial infarction [33], and brain injury [16, 34]. Taken together, our study supports a positive regulatory role for TSG- 6 released by ASCs in the amelioration of visual deficits of mTBI. Most importantly, this work broadens our understanding of the direct effects of TSG-6 on multiple cell types within the retina in establishing a cell signaling environment that protects visual processing from the effects of acute blast injury (Fig. 8).

TSG-6 is a $30-\mathrm{kDa}$ anti-inflammatory protein expressed by MSCs but also monocytes and macrophages [12]. A variety of pro-inflammatory stimuli have been shown to upregulate TSG-6 that include TNF $\alpha$, IL1 $\beta$, and LPS [35]. Although the exact mechanism through which TSG-6 elicits its anti-inflammatory effects is not fully understood, it is known to polarize macrophages from a pro-inflammatory to anti-inflammatory phenotype in a STAT1 and STAT3 dependent pathway [28]. To this end, BV2 microglia treated with ASC-CCM that lacks TSG-6 failed to suppress nitrite release, pro-inflammatory gene expression, and STAT3 phosphorylation after LPS stimulation, suggesting a key role for TSG-6 in microglial activation released by ASCs. Furthermore, both arborization of microglial cells as assessed by F-actin staining and increased Iba-1 immunostaining in BV2 cells were abrogated by siControl ASC-CCM but not the siTSG-6-ASC-CCM. The microglia have the capacity to shift a cell-to-cell signaling microenvironment from neurotoxic to neuroprotective depending on the type of injury, tissue location, and the timing of assessment. Consequently, we utilized NanoString gene expression analysis to better understand how treatment altered the injury environment via changes in microglial-related genes. The analysis revealed that more than 20 genes were upregulated in blast injury animals 4 weeks post-blast injury. For example, interferon response pathway genes such as the Irf8 transcription factor, Ccl5 and Cxcl10, and TNF signaling genes such as Tnf and Ill $\beta$ were upregulated by at least twofold in blast injury retina, while they were found to be downregulated in the siControl ASC-CCM-treated retina. Interestingly, our TaqMan assays for both Irf8 and Il1b confirmed this differential expression and a significant rescue with siControl ASC-CCM, which is in line with the association of these genes with microglia and $\operatorname{mTBI}[36,37]$. Collectively, these studies validate the hypothesis that TSG6 is required for the beneficial outcomes of ASC-CCM on 


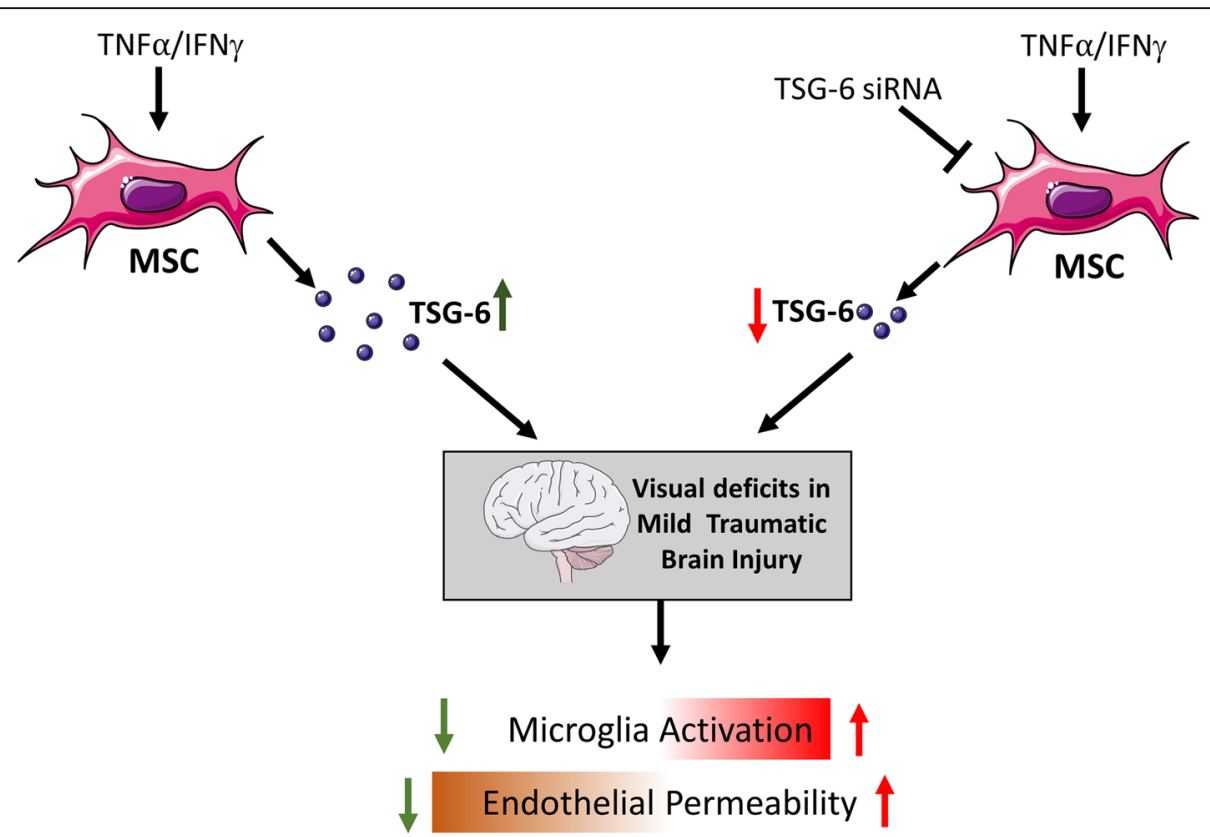

Fig. 8 Schematic model of TSG-6 in conditioned media from adipose mesenchymal stem cells protects against visual deficits in mild traumatic brain injury model through neurovascular modulation. Direct effects of TSG-6 on multiple cell types within the retina in establishing a cell signaling environment that protects visual processing from the effects of acute blast injury via decreased microglial and endothelial activation and protection against loss of endothelial permeability. Created with content from Servier Medical Art (https://smart.servier.com) under Creative Commons Attribution 3.0 Unported license (https://creativecommons.org/licenses/by/3.0/)

microglia. These studies indicate that TSG-6 in ASC-CCM is required for the observed outcomes; however, considering the fact that some microglial-associated gene expression was also altered with siTSG-6-ASC-CCM, TSG-6 alone may be insufficient to recapitulate the full breadth of the observed therapeutic effect.

Several anti-inflammatory agents have been used in animal models with limited benefits with some used in clinical trials of TBI failed [38-41]. Acute exposure of TSG-6 has been shown to prevent neurodegeneration in a TBI animal model resulting in improved long-term memory and behavioral disability [42]. In accordance with this finding, our study has shown a neuroprotective role of TSG-6 released by ASC-CCM in the rescue of visual deficits in our mTBI model. Only the siControl-ASC-CCM but not siTSG-6ASC-CCM improved visual acuity and contrast sensitivity in the mice. These observations are also in agreement with our previous observations of improvement in optokinetic measurements in TBI mice [11]. Additionally, ERG analysis demonstrated amelioration of b-wave, a bipolar response that is suppressed in blast injury retina with siControlASC-CCM. Interestingly, animals that received siTSG-6ASC-CCM also showed improvement, suggesting molecules other than TSG-6 in ASC-CCM affect the bipolar response. On the other hand, since the siControl-ASC-CCM but not siTSG-6-ASC-CCM reduced GFAP expression in the inner retina, TSG-6 appears to play a role in preventing of Muller cell gliosis. Given the critical supportive role of Muller cells to retinal ganglion cells, normalization of Muller cell phenotype and function may result in improved function of retinal ganglion cells and the processing of visual signals to the optic nerve. Increased distribution of GFAP throughout Muller glia is a common feature of a variety of retinal diseases, and correlates with neuronal degeneration and loss, resulting in retinal thinning, observed in animal models [43]. We previously observed a focal loss of neuronal cells in the GCL of blast retina [11]. Taken together, our data suggest that the trophic factors specifically TSG-6 from ASCs may rescue ganglion cell or other neuronal cell damage in the blast retina indirectly via the Muller cells.

A growing number of neurological diseases are characterized by a highly vascular phenotype. Considering the fact that TBI is represented with a compromised bloodbrain barrier [44], we anticipated the loss of the endothelial barrier in our mTBI model. Therefore, we tested endothelial cell permeability stimulated with TNF $\alpha$ in the absence of immune cells and observed a critical role for TSG-6 in normalizing permeability mainly by preserving the endothelial adherens junctions as observed with VE-cadherin immunostaining and downregulation of STAT3 phosphorylation. Consequently, the role of TSG-6 extends beyond shifting microglial and/or macrophage polarization observed in other studies and may serve as an important regenerative agent to block pro-inflammatory signaling initiated by immune cells on the endothelial cells recruited to 
the sites of blast injury. Future studies will aim to understand if TSG-6 in ASC-CCM could protect against increased vascular permeability in vivo.

It has been shown that TSG-6 acts via the STAT3 pathway [28]. Various cytokines including IFN $\gamma$, growth factors, and G-protein coupled receptors induce STAT3 phosphorylation $[45,46]$, demonstrating that diverse pathways lead to STAT3 activation. Upon its activation, STAT3 subsequently translocates into the nucleus where it stimulates the transcription of genes, resulting in either anti-inflammatory effects [47] or pro-inflammatory effects [48]. Specifically in retinal inflammation, activated STAT3 expression is increased in the ganglion cell, inner nuclear, and photoreceptors layers, therefore linking STAT3 to a pro-inflammatory effect and subsequent excessive degradation of proteins required for visual function [49]. In support of our observation that ASCs respond to proinflammatory cytokines by secreting a higher concentration of TSG-6 that suppresses pro-inflammatory microglial and endothelial activation in a STAT3 dependent pathway, human MSCs are found to be neuroprotective in optic neuropathies through suppression of STAT3 and other pathways [50]. More studies are warranted to better understand the regulation of STAT3 in our mTBI model and its link to neurovascular degeneration.

Since TSG-6 expression in ASC-CCM mediates many of the observed therapeutic benefits of ASC-CCM in our model, direct administration of TSG-6 may likely have therapeutic activity. In support of this hypothesis, a recent study suggested that acute administration of TSG-6 showed remarkable improvement in memory after TBI [42]. However, it must be noted that TSG-6 was effective only when administered during the initial and mild phase of an inflammatory reaction in a corneal mechanical injury model [20] with no therapeutic benefit in a corneal alkali injury model [51]. This suggests that TSG-6 alone may not likely to prevent ongoing tissue degeneration in TBI, while on the other hand, the powerful antioxidant and immunomodulatory proteins in addition to TSG-6 in ASC-CCM will not only suppress ongoing inflammation but also aid in the regeneration.

\section{Conclusions}

In conclusion, our findings suggest that ASCs respond to an inflammatory milieu by secreting several therapeutically valuable proteins among which TSG- 6 expression correlated with the therapeutic potency of ASC-CCM. ASCs engineered to produce TSG- 6 will be an invaluable regenerative therapy solution against the traumatic effects of blast injuries to the retina with potential broader applications to other degenerative central nervous system diseases. Alternatively, processes to improve the production of key analytes such as TSG-6 in ASCs may serve to develop better secretome-derived biologics for the treatment against the traumatic effects of blast injuries to the retina as well as other inflammatory conditions.

\section{Supplementary information}

Supplementary information accompanies this paper at https://doi.org/10. 1186/s13287-019-1436-1.

Additional file 1: Figure S1. Experimental time line. About 12-week old C57BI/6j mice were used in the study. Two independent experiments were performed with the same donor-derived ASC-CM. Live retinal function experiments were performed after 4 weeks of intravitreal injection followed by euthanasia and molecular and histological analyses.

Additional file 2: Figure S2. Depletion of TSG-6 from cytokine primed ASC conditioned medium is target specific. Immunoblot analysis of TSG-6 in cell lysates and CCM. GAPDH and TIMP1 in CCM remained unchanged. Data represent a single experiment.

Additional file 3: Figure S3. Depletion of TSG-6 from ASC-CCM fails to improve microglial morphology. Microglial morphology after the LPS $(100 \mathrm{ng} / \mathrm{ml})$ and IFNy $(10 \mathrm{ng} / \mathrm{ml})$ exposure and challenged with siControl ASC-CCM or siTSG-6 ASC-CCM as shown by F-actin stained confocal micrographs. Scale bars $=20 \mu \mathrm{m}$. Data represent a single experiment performed in duplicates.

Additional file 4: Figure S4. Depletion of TSG-6 from ASC-CCM improves retinal function and vision in blast injury mice. (A): b-wave amplitude measurement in mice at various flash intensities (B): b-wave amplitude at $25 \mathrm{~cd} . \mathrm{s} . \mathrm{cm}^{2}$ expressed as $\mu \mathrm{V}$. Data represent combined Mean \pm SEM from $n=8-19$ animals/group of the left eye only performed in 2 separate batches. ${ }^{*} p<0.05 ;{ }^{* *} p<0.01 ;{ }^{* * *}, p<0.001$.

Additional file 5: Figure S5. Differential gene expression in blast injury mice without and with primed siControl-ASC-CCM and primed SiTSG-6ASC-CCM. (A): Heatmap representing the directed global significance score for the represented group comparisons calculated as the square root of the mean signed squared t-statistic for the genes in a gene set, with t-statistics coming from the linear regression underlying the differential expression analysis. (B): Volcano plot displaying each gene's -log10 ( $p$-value) and $\log 2$ fold change with the selected covariate. Highly statistically significant genes fall at the top of the plot above the horizontal lines, and highly differentially expressed genes fall to either side. Horizontal lines indicate various False Discovery Rate (FDR) thresholds or p-value thresholds if there is no adjustment to the $p$-values. Genes are colored if the resulting $p$-value is below the given FDR or p-value threshold. The 40 most statistically significant genes are labeled in the plot. (C): Representative violin plots of differentially expressed genes in all four study groups. (D): Venn diagram showing significant differentially expressed genes. Data represent combined averages from $n=4-9$ animals/group using NanoString Advanced Analysis.

\section{Acknowledgements}

The authors wish to acknowledge Erica Pawlak, Ph.D., for the technical assistance with NanoString data analysis.

\section{Authors' contributions}

$K A J, M P, R L$, and LK were responsible for the design, collection, and assembly of the data; data analysis and interpretation; and manuscript writing. CY, JG, and NDM were responsible for the collection and assembly of the data. AR, LMP, and NS were responsible for the conception and design, data analysis and interpretation, and manuscript writing. RG was responsible for the conception and design, collection and assembly of data, data analysis and interpretation, and manuscript writing. All authors read and approved the final manuscript.

\section{Funding}

This study was funded by grants from the Department of Defense (W81XWH-16-1-0761), National Eye Institute (EY023427), and unrestricted funds from Research to Prevent Blindness to RG and Department of Defense (W81XWH-16-1-0076) to AR. KAJ is a recipient of a postdoc fellowship award 
from the Neuroscience Institute, UTHSC. The funders played no role in the conduct of the study, collection of data, management of the study, analysis of data, interpretation of data, or preparation of the manuscript.

\section{Availability of data and materials}

All data generated and/or analyzed during this study are included in this published article. Data sharing is not applicable to this article as no datasets were generated or analyzed during the current study. However, the data that support the findings of this study including details of NanoString gene expression analysis are available from the corresponding author upon reasonable request.

\section{Ethics approval and consent to participate}

Studies involving human adipose tissue were approved by the UTHSC Institutional Review Board in accordance with relevant guidelines and regulations following the tenets of the Declaration of Helsinki. Institutional IRB approved the study as exempt since the study involved de-identified cell lines from commercial sources, and therefore, consent to participate does not apply. All animal studies were conducted according to our previously published protocol [11] and were approved by the Institutional Animal Care and Use Committee, UTHSC, Memphis (IACUC ID: 16-110) and USAMRMC Animal Care and Use Review Office (Protocol No. VR150072) following the guidelines DOD Instruction 3216.01, "Use of Animals in DOD Programs."

\section{Consent for publication}

Not applicable.

\section{Competing interests}

NS and RG are co-founders and hold equity in Cell Care Therapeutics, Inc., whose interest is in the use of adipose-derived stromal cells in visual disorders. MP and LK are employees of Cell Care Therapeutics, Inc. with equity. All other authors declare that they have no competing interests.

\section{Author details}

'Department of Ophthalmology, University of Tennessee Health Science Center, College of Medicine, 930 Madison Ave, Suite\#768, Memphis, TN 38163, USA. ${ }^{2}$ Cell Care Therapeutics, Inc., Los Angeles, CA, USA. ${ }^{3}$ Present Address: Pathways to Stem Cell Science, Monrovia, CA, USA. ${ }^{4}$ Department of Anatomy and Neurobiology, University of Tennessee Health Science Center, College of Medicine, 855 Monroe Avenue, Suite\#515, Memphis, TN 38163, USA. ${ }^{5}$ Department of Pathology, University of Tennessee Health Science Center, College of Medicine, 19 South Manassas Street, Suite\#214, Memphis, TN 38163, USA.

Received: 4 June 2019 Revised: 21 September 2019 Accepted: 30 September 2019 Published online: 05 November 2019

\section{References}

1. DoD Worldwide Numbers for TBI. http://dvbic.dcoe.mil/dod-worldwidenumbers-tbi. Accessed 6 Nov 2018.

2. Weichel ED, Colyer MH, Ludlow SE, Bower KS, Eiseman AS. Combat ocular trauma visual outcomes during operations Iraqi and enduring freedom. Ophthalmology. 2008;115(12):2235-45.

3. Brahm KD, Wilgenburg HM, Kirby J, Ingalla S, Chang CY, Goodrich GL. Visual impairment and dysfunction in combat-injured service members with traumatic brain injury. Optom Vis Sci. 2009;86(7):817-25.

4. Guley NH, Rogers JT, Del Mar NA, Deng Y, Islam RM, D'Surney L, Ferrell J, Deng B, Hines-Beard J, Bu W, Ren H, Elberger AJ, Marchetta JG, Rex TS, Honig MG, Reiner A. A novel closed-head model of mild traumatic brain injury using focal primary overpressure blast to the cranium in mice. J Neurotrauma. 2016;33(4):403-22.

5. Mammadova N, Ghaisas S, Zenitsky G, Sakaguchi DS, Kanthasamy AG, Greenlee JJ, West Greenlee MH. Lasting retinal injury in a mouse model of blast-induced trauma. Am J Pathol. 2017;187(7):1459-72.

6. Kumar A, Alvarez-Croda DM, Stoica BA, Faden Al, Loane DJ. Microglial/ macrophage polarization dynamics following traumatic brain injury. J Neurotrauma. 2016;33(19):1732-50.

7. Redell JB, Dash PK. Traumatic brain injury stimulates hippocampal catechol-Omethyl transferase expression in microglia. Neurosci Lett. 2007;413(1):36-41.
8. Das M, Mohapatra S, Mohapatra SS. New perspectives on central and peripheral immune responses to acute traumatic brain injury. J Neuroinflammation. 2012;9:236.

9. Perez-Polo JR, Rea HC, Johnson KM, Parsley MA, Unabia GC, Xu G, Infante SK, Dewitt DS, Hulsebosch CE. Inflammatory consequences in a rodent model of mild traumatic brain injury. J Neurotrauma. 2013;30(9):727-40.

10. Cao T, Thomas TC, Ziebell JM, Pauly JR, Lifshitz J. Morphological and genetic activation of microglia after diffuse traumatic brain injury in the rat. Neuroscience. 2012;225:65-75.

11. Jha KA, Pentecost M, Lenin R, Klaic L, Elshaer SL, Gentry J, Russell JM, Beland A, Reiner A, Jotterand V, Sohl N, Gangaraju R. Concentrated conditioned media from adipose tissue derived mesenchymal stem cells mitigates visual deficits and retinal inflammation following mild traumatic brain injury. Int J Mol Sci. 2018;19(7):E2016.

12. Prockop DJ. Inflammation, fibrosis, and modulation of the process by mesenchymal stem/stromal cells. Matrix Biol. 2016;51:7-13.

13. Kim SJ, Lee HJ, Yun JH, Ko JH, Choi DY, Oh JY. Intravitreal TSG-6 suppresses laser-induced choroidal neovascularization by inhibiting CCR2+ monocyte recruitment. Sci Rep. 2015;5:11872.

14. Tuo J, Cao X, Shen D, Wang Y, Zhang J, Oh JY, Prockop DJ, Chan CC. Antiinflammatory recombinant TSG-6 stabilizes the progression of focal retinal degeneration in a murine model. J Neuroinflammation. 2012;9:59.

15. Elshaer SL, Evans W, Pentecost M, Lenin R, Periasamy R, Jha KA, Alli S, Gentry J, Thomas SM, Sohl N, Gangaraju R. Adipose stem cells and their paracrine factors are therapeutic for early retinal complications of diabetes in the Ins2(Akita) mouse. Stem Cell Res Ther. 2018;9(1):322.

16. Li R, Liu W, Yin J, Chen Y, Guo S, Fan H, Li X, Zhang X, He X, Duan C. TSG-6 attenuates inflammation-induced brain injury via modulation of microglial polarization in SAH rats through the SOCS3/STAT3 pathway. J Neuroinflammation. 2018;15(1):231.

17. Li Q, Song WJ, Ryu MO, Nam A, An JH, Ahn JO, Bhang DH, Jung YC, Youn HY. TSG-6 secreted by human adipose tissue-derived mesenchymal stem cells ameliorates severe acute pancreatitis via ER stress downregulation in mice. Stem Cell Res Ther. 2018;9(1):255.

18. Di G, Du X, Qi X, Zhao X, Duan H, Li S, Xie L, Zhou Q. Mesenchymal stem cells promote diabetic corneal epithelial wound healing through TSG-6dependent stem cell activation and macrophage switch. Invest Ophthalmol Vis Sci. 2017;58(10):4344-54.

19. Swaidani S, Cheng G, Lauer ME, Sharma M, Mikecz K, Hascall VC, Aronica MA. TSG-6 protein is crucial for the development of pulmonary hyaluronan deposition, eosinophilia, and airway hyperresponsiveness in a murine mode of asthma. J Biol Chem. 2013;288(1):412-22.

20. Oh JY, Roddy GW, Choi H, Lee RH, Ylostalo JH, Rosa RH Jr, Prockop DJ. Antiinflammatory protein TSG-6 reduces inflammatory damage to the cornea following chemical and mechanical injury. Proc Natl Acad Sci U S A. 2010; 107(39):16875-80.

21. Liu Y, Zhang R, Yan K, Chen F, Huang W, Lv B, Sun C, Xu L, Li F, Jiang X. Mesenchymal stem cells inhibit lipopolysaccharide-induced inflammatory responses of BV2 microglial cells through TSG-6. J Neuroinflammation. 2014;11:135

22. Heldt SA, Elberger AJ, Deng Y, Guley NH, Del Mar N, Rogers J, Choi GW, Ferrell J, Rex TS, Honig MG, Reiner A. A novel closed-head model of mild traumatic brain injury caused by primary overpressure blast to the cranium produces sustained emotional deficits in mice. Front Neurol. 2014;5:2.

23. Ganguly D, Sims M, Cai C, Fan M, Pfeffer LM. Chromatin remodeling factor BRG1 regulates stemness and chemosensitivity of glioma initiating cells. Stem Cells. 2018;36(12):1804-15.

24. Lenin R, Nagy PG, Alli S, Rao VR, Clauss MA, Kompella UB, Gangaraju R. Critical role of endoplasmic reticulum stress in chronic endothelial activation-induced visual deficits in tie2-tumor necrosis factor mice. J Cell Biochem. 2018;119(10):8460-71.

25. Lenin R, Nagy PG, Gentry J, Gangaraju R. Deterioration of visual function mediated by senescence-associated endoplasmic reticulum stress in inflammatory tie2-TNF mice. Exp Biol Med (Maywood). 2018;243(12):976-84.

26. Presley C, Abidi A, Suryawanshi S, Mustafa S, Meibohm B, Moore BM. Preclinical evaluation of SMM-189, a cannabinoid receptor 2-specific inverse agonist. Pharmacol Res Perspect. 2015;3(4):e00159.

27. Duan L, Chen BY, Sun XL, Luo ZJ, Rao ZR, Wang JJ, Chen LW. LPS-induced proNGF synthesis and release in the N9 and BV2 microglial cells: a new pathway underling microglial toxicity in neuroinflammation. PLoS One. 2013;8(9):e73768. 
28. Mittal M, Tiruppathi C, Nepal S, Zhao YY, Grzych D, Soni D, Prockop DJ, Malik AB. TNFalpha-stimulated gene-6 (TSG6) activates macrophage phenotype transition to prevent inflammatory lung injury. Proc Natl Acad Sci U S A. 2016:113(50):E8151-8.

29. Yun JH, Park SW, Kim KJ, Bae JS, Lee EH, Paek SH, Kim SU, Ye S, Kim JH, Cho $\mathrm{CH}$. Endothelial STAT3 activation increases vascular leakage through downregulating tight junction proteins: implications for diabetic retinopathy. J Cell Physiol. 2017;232(5):1123-34.

30. Rajashekhar G, Ramadan A, Abburi C, Callaghan B, Traktuev DO, EvansMolina C, Maturi R, Harris A, Kern TS, March KL. Regenerative therapeutic potential of adipose stromal cells in early stage diabetic retinopathy. PLoS One. 2014;9(1):e84671.

31. Cahoon JM, Rai RR, Carroll LS, Uehara H, Zhang X, O'Neil CL, Medina RJ, Das SK, Muddana SK, Olson PR, Nielson S, Walker K, Flood MM, Messenger WB, Archer BJ, Barabas P, Krizaj D, Gibson CC, Li DY, Koh GY, Gao G, Stitt AW, Ambati BK. Intravitreal AAV2.COMP-Ang1 prevents neurovascular degeneration in a murine model of diabetic retinopathy. Diabetes. 2015; 64(12):4247-59.

32. Danchuk S, Ylostalo JH, Hossain F, Sorge R, Ramsey A, Bonvillain RW, Lasky JA, Bunnell BA, Welsh DA, Prockop DJ, Sullivan DE. Human multipotent stromal cells attenuate lipopolysaccharide-induced acute lung injury in mice via secretion of tumor necrosis factor-alpha-induced protein 6. Stem cell Res Ther. 2011;2(3):27.

33. Lee RH, Pulin AA, Seo MJ, Kota DJ, Ylostalo J, Larson BL, Semprun-Prieto L, Delafontaine P, Prockop DJ. Intravenous hMSCs improve myocardial infarction in mice because cells embolized in lung are activated to secrete the anti-inflammatory protein TSG-6. Cell Stem Cell. 2009;5(1):54-63.

34. Zhang R, Liu Y, Yan K, Chen L, Chen XR, Li P, Chen FF, Jiang XD. Antiinflammatory and immunomodulatory mechanisms of mesenchymal stem cell transplantation in experimental traumatic brain injury. J Neuroinflammation. 2013;10:106.

35. Wisniewski HG, Maier R, Lotz M, Lee S, Klampfer L, Lee TH, Vilcek J. TSG-6: a TNF-, IL-1-, and LPS-inducible secreted glycoprotein associated with arthritis. J Immunol. 1993;151(11):6593-601.

36. Taib T, Leconte C, Van Steenwinckel J, Cho AH, Palmier B, Torsello E, Lai Kuen R, Onyeomah S, Ecomard K, Benedetto C, Coqueran B, Novak AC, Deou E, Plotkine M, Gressens P, Marchand-Leroux C, Besson VC. Neuroinflammation, myelin and behavior: Temporal patterns following mild traumatic brain injury in mice. PLoS One. 2017;12(9):e0184811.

37. Masuda T, Tsuda M, Yoshinaga R, Tozaki-Saitoh H, Ozato K, Tamura T, Inoue $K$. IRF8 is a critical transcription factor for transforming microglia into a reactive phenotype. Cell Rep. 2012;1(4):334-40.

38. Xiao G, Wei J, Yan W, Wang W, Lu Z. Improved outcomes from the administration of progesterone for patients with acute severe traumatic brain injury: a randomized controlled trial. Crit Care. 2008;12(2):R61.

39. Vonder Haar C, Anderson GD, Elmore BE, Moore LH, Wright AM, Kantor ED, Farin FM, Bammler TK, MacDonald JW, Hoane MR. Comparison of the effect of minocycline and simvastatin on functional recovery and gene expression in a rat traumatic brain injury model. J Neurotrauma. 2014;31(10):961-75.

40. Haber M, Abdel Baki SG, Grin'kina NM, Irizarry R, Ershova A, Orsi S, Grill RJ, Dash P, Bergold PJ. Minocycline plus N-acetylcysteine synergize to modulate inflammation and prevent cognitive and memory deficits in a rat model of mild traumatic brain injury. Exp Neurol. 2013;249:169-77.

41. Hoffer ME, Balaban C, Slade MD, Tsao JW, Hoffer B. Amelioration of acute sequelae of blast induced mild traumatic brain injury by $\mathrm{N}$-acetyl cysteine: a double-blind, placebo controlled study. PLoS One. 2013;8(1):e54163.

42. Watanabe J, Shetty AK, Hattiangady B, Kim DK, Foraker JE, Nishida H, Prockop DJ. Administration of TSG-6 improves memory after traumatic brain injury in mice. Neurobiol Dis. 2013;59:86-99.

43. landiev I, Biedermann B, Bringmann A, Reichel MB, Reichenbach A, Pannicke T. Atypical gliosis in Muller cells of the slowly degenerating rds mutant mouse retina. Exp Eye Res 2006;82(3):449-457.

44. Menge T, Zhao Y, Zhao J, Wataha K, Gerber M, Zhang J, Letourneau P, Redell J, Shen L, Wang J, Peng Z, Xue H, Kozar R, Cox CS Jr, Khakoo AY, Holcomb JB, Dash PK, Pati S. Mesenchymal stem cells regulate blood-brain barrier integrity through TIMP3 release after traumatic brain injury. Sci Transl Med. 2012:4(161):161ra150.

45. Brennan CW, Verhaak RG, McKenna A, Campos B, Noushmehr H, Salama SR, Zheng S, Chakravarty D, Sanborn JZ, Berman SH, Beroukhim R, Bernard B, Wu CJ, Genovese G, Shmulevich I, Barnholtz-Sloan J, Zou L, Vegesna R,
Shukla SA, Ciriello G, Yung WK, Zhang W, Sougnez C, Mikkelsen T, Aldape K, Bigner DD, Van Meir EG, Prados M, Sloan A, Black KL, Eschbacher J, Finocchiaro G, Friedman W, Andrews DW, Guha A, lacocca M, O'Neill BP, Foltz G, Myers J, Weisenberger DJ, Penny R, Kucherlapati R, Perou CM, Hayes DN, Gibbs R, Marra M, Mills GB, Lander E, Spellman P, Wilson R, Sander C, Weinstein J, Meyerson M, Gabriel S, Laird PW, Haussler D, Getz G, Chin L, Network TR. The somatic genomic landscape of glioblastoma. Cell. 2013;155(2):462-77.

46. Jiang SY, Li LL, Yue J, Chen WZ, Yang C, Wan CL, He L, Cai L, Deng SL. The effects of SP110's associated genes on fresh cavitary pulmonary tuberculosis in Han Chinese population. Clin Exp Med. 2016;16(2):219-25.

47. Hutchins AP, Poulain S, Miranda-Saavedra D. Genome-wide analysis of STAT3 binding in vivo predicts effectors of the anti-inflammatory response in macrophages. Blood. 2012;119(13):e110-9.

48. Pawlowska E, Szczepanska J, Koskela A, Kaarniranta K, Blasiak J. Dietary polyphenols in age-related macular degeneration: protection against oxidative stress and beyond. Oxidative Med Cell Longev. 2019;2019:9682318.

49. Ozawa Y, Nakao K, Kurihara T, Shimazaki T, Shimmura S, Ishida S, Yoshimura A, Tsubota K, Okano H. Roles of STAT3/SOCS3 pathway in regulating the visual function and ubiquitin-proteasome-dependent degradation of rhodopsin during retinal inflammation. J Biol Chem. 2008;283(36):24561-70.

50. Osborne A, Sanderson J, Martin KR. Neuroprotective effects of human mesenchymal stem cells and platelet-derived growth factor on human retinal ganglion cells. Stem Cells. 2018;36(1):65-78.

51. Choi H, Phillips C, Oh JY, Potts L, Reger RL, Prockop DJ, Fulcher S. Absence of therapeutic benefit of the anti-inflammatory protein TSG-6 for corneal alkali injury in a rat model. Curr Eye Res. 2019;44(8):873-81.

\section{Publisher's Note}

Springer Nature remains neutral with regard to jurisdictional claims in published maps and institutional affiliations.

\section{Ready to submit your research? Choose BMC and benefit from:}

- fast, convenient online submission

- thorough peer review by experienced researchers in your field

- rapid publication on acceptance

- support for research data, including large and complex data types

- gold Open Access which fosters wider collaboration and increased citations

- maximum visibility for your research: over $100 \mathrm{M}$ website views per year

At BMC, research is always in progress.

Learn more biomedcentral.com/submissions 